\title{
Impact of Selection on Distribution of Crop Duration Parameters in Chinese Wheat Hybrids
}

\author{
Zainab Iftikhar ${ }^{1}$, Muhammad Arif ${ }^{2}$ Iqbal Munir ${ }^{1}$ and Sajid Ali ${ }^{*}$
}

${ }^{1}$ Institute of Biotechnology and Genetic Engineering, The University of Agriculture, Peshawar, Pakistan; ${ }^{2}$ Department of Agronomy, The University of Agriculture, Peshawar, Pakistan.

\begin{abstract}
Changes in climatic conditions would strongly influence the crop duration of many crops including wheat, which necessitates exploration of diversity in crop duration parameters in wheat with particular emphasis on novel sources of genetic variation, including hybrid wheat. The present work was designed to assess the potential of Chinese wheat hybrid germplasm for cultivation across Pakistan. For this purpose, 416 hybrids were assessed for diversity in crop duration parameters in the year 2017-18 and a subset of better performing 108 hybrids were selected and assessed for subsequent assessment. During the first experiment of preliminary testing of 416 Chinese wheat hybrids along with 5 local checks tested during 2017-18, significant variability $(\mathrm{P}<0.01)$ was observed for days to jointing and booting, the parameters related to crop duration. The overall impact was negative on the crop duration, resulting in selection of earlier lines. Although selection increased the mean value, the variability decreased for most of the parameters. Variability in Chinese hybrids reflects on the potential of selection for candidate hybrids to be released in Pakistan after proper testing. The variability could also be exploited for generation of further variability in Pakistani wheat germplasm for normal varietal development as a novel source of germplasm to reduce genetic homogeneity.

Received | March 20, 2021; Accepted | July 07, 2021; Published | August 24, 2021

*Correspondence | Sajid Ali, Institute of Biotechnology and Genetic Engineering, The University of Agriculture, Peshawar, Pakistan; Email: bioscientist122@yahoo.com

Citation | Iftikhar Z., M. Arif, I. Munir and S. Ali. 2021. Impact of selection on distribution of crop duration parameters in Chinese wheat hybrids. Sarhad Journal of Agriculture, 37(4): 1178-1193.

DOI | https://dx.doi.org/10.17582/journal.sja/2021/37.4.1178.1193

Keywords | Chinese lines, hybrid wheat, earliness traits, maturity parameters, selection
\end{abstract}

\section{Introduction}

W Theat crop production has enormously increased in the post Green Revolution decades due to the use of semi dwarf varieties of wheat in $\mathrm{Pa}$ kistan and India like Mexi-Pak, Sonalika and Kalyan Sona (Ziska et al., 2012). Green Revolution, however, has resulted in exploitation of limited crop diversity in countries like Pakistan, where most of the wheat germplasm is based on CIMMYT introduced material (Ali et al., 2014c). Further increase in yield is relatively slow due to its narrow genetic background, particularly in semiarid areas, especially in the context of changing climate. The crop duration is strongly influenced by the changes in climatic conditions, especially temperature and rainfall. The available diversity in Pakistani germplasm provides limited variability to carry out breeding for earliness and other crop duration parameters. It becomes more complicated while considering diseases, where many varieties have been shown to be overcome by the highly adaptive rust pathogens (Ali et al., 2014a), mainly due to limited diversity in sources of genetic resistance (Ali et al., 2014c). Thus, an efficient genetic improvement programme necessitates exploitation of novel/exotic sources of diversity, ranging from sources in wild rel- 
atives to hybrid wheat.

For the exotic germplasm, the performance of lines may vary when introduced into a novel area and thus, testing of exotic germplasm is a pre-requisite for further breeding (Qasim et al., 2008). However, a large number of lines are introduced at the first point to capture the maximum diversity, thus, thorough phenotyping is quite difficult. Preliminary testing is, thus, the first step to characterize a large set of germplasm (Fufa et al., 2005; Perween et al., 2020). After preliminary testing, selection could be made to proceed with cultivars or hybrids with desirable trait, though passing through a risk of genetic drift, where some desirable lines could be lost due to limited information about the germplasm during the preliminary testing (Aycicek and Yildirim 2006; Singh et al., 2016). The effectiveness of the selection for both, quantitative and qualitative traits, depend on the genetic variability and heritability (Khan and Hassan 2018). Field based preliminary testing in various parameters is essential in order to quantify the phenotypic variation, while exploring genetic resources not exploited in the past in Pakistan, like the ones from Chinese wheat germplasm, including Chinese wheat hybrids.

The hybrid breeding seems to be an effective process employed in removing the obstacles in higher wheat yield, when approached a stagnancy in the varietal development. Greater profit from heterosis and a large return on investment could be attained because of an in-built varietal phytoprotection which makes hybrid breeding recommendable in comparison to line breeding. The gain from hybrid vigour is a routine process in cross pollinated crops like maize, and regular hybrids are registered on annual basis for subsequent dissipation to the farmers. These hybrids have been shown to increase the yields of various crops in different parts of the world. However, reduction of inbred lines and subsequent production of hybrid seed is a limiting factor in many crops. A prominent gain in selection, an inexpensive production and availability of hybrid seed and enough heterosis levels are needed for success of a hybrid wheat breeding program (Longin et al. 2012). The hybrid vigour needs to be used commercially through developing hybrid wheat varieties which could likely overcome the food shortcomings due to yield heterosis (Singh et al. 2004). The additional hybrid seed expenditures, comparatively lower seed multiplying rate and complex hybridizing systems are the limiting factors to pro- duce hybrid wheat's growth and sales of seeds along with insufficient amount of heterosis in a number of ecological conditions (Edwards 2001). Exploration of the potential of hybrid wheat varieties is under intensive assessment to improve wheat yield in China. Chinese wheat represents a diverse source of wheat gene pool, which could potentially be exploited in $\mathrm{Pa}-$ kistan for wheat genetic improvement. Additionally, the potential of Hybrid wheat remains unexplored in Pakistan.

Our work is designed with an aim to explore diversity among Chinese hybrids for their suitability in the wheat production in Pakistan, based on preliminary testing and their response to selection. Comparison of the performance of hybrid lines with local checks will enable to estimate commercial heterosis. The information in the preliminary trial is not only important for selection of parents with better performance to be crossed, but is also important for selection of better performing $\mathrm{F}_{1}$ hybrids, which could be directly recommended for cultivation after thorough testing. These studies on Chinese hybrids could enable to explore useful genes in the rich allelic stock of hybrids, which have been developed from Chinese landraces and wheat cultivars (Peleg et al., 2009; Dresselhaus and Hu"ckelhoven 2018). The hybrids studied in the current study are based on the male sterility traits and considering their Chinese origin, these are well suited to be considered under Pakistani wheat production system.

The present study was, thus, designed to explore diversity for crop duration parameters in Chinese hybrids and the impact of selection in terms of changes in the distribution of these parameters. The performance of selected hybrids was, further, assessed based on field testing while estimating selection differential and genetic advance.

\section{Materials and Methods}

A set of 416 Chinese Hybrids, received from Beijing Engineering Research Centre for Hybrid Wheat (BERCHW), China, was assessed for its phenotypic diversity along with five checks in the first year, whereas a subset of selected 108 Chinese Hybrids was assessed during the second year for evaluation. Both the preliminary testing and evaluation of selected material was carried out at the experimental field of Sheerin Khan Research Farm, the University of Agriculture, Peshawar, Pakistan $\left(34^{\circ} 1^{\prime} 21^{\prime \prime} \mathrm{N}, 71^{\circ} 28^{\prime} 5^{\prime \prime} \mathrm{E}\right)$. 
The experimental site had subtropical climate, with semi-arid conditions, receiving annual rainfall of 360 $\mathrm{mm}$.

\section{Preliminary field testing of 416 Chinese wheat hybrids} The preliminary trial comprised of 416 Chinese wheat hybrids and 5 check varieties viz., Atta Habib, Shahkar-13, PirSabak-15, Ghanimat-e-IBGE and PirSabak-13 (Table 1). The aim of this experiment was to assess the preliminary field-based diversity among these Chinese hybrids in comparison with the local checks. Data was collected on crop duration parameters i.e., days to emergence, jointing, booting, heading, anthesis and maturity (Maqbool et al., 2010; Khan and Hassan, 2018). The field experimentation and crop husbandry were followed as per routine wheat production technology at the research farm.

The trial was carried out in an augmented design, which consisted of 8 blocks, 25 plots and 22 subplots. The sub-plots consisted of two rows of 1.5 meter length with $25 \mathrm{~cm}$ row spacing. Each block was divided into a plot and then, subplot, having seventeen hybrids and five check varieties, which was repeated to calculate the error mean square and block effect, as per standard procedure of augmented design. Wheat hybrids were sown on a well-prepared seedbed during November in winter with hand hoe, maintaining row to row distance of $25 \mathrm{~cm}$. Crop husbandry was done as per recommended practices. Planting was done at the seeding rate of 50 seeds plot $^{-1}$. A basal dose of phosphorus and potassium each at the rate of 90 and $50 \mathrm{~kg} \mathrm{ha}{ }^{-1}$ was applied in the form of DAP (Di-ammonium Phosphate) and Sulphate of potash (SOP), respectively. Nitrogen at the rate of $150 \mathrm{~kg} \mathrm{ha}^{-1}$ was applied in two splits; half was applied with first irrigation while remaining half was applied at jointing stage. First irrigation was applied four weeks after sowing the crop while subsequent irrigations were applied as and when needed. Affinity 50WP (Isoproturon + Carfentrazone) @ $2 \mathrm{~kg} \mathrm{ha}^{-1}\left(800 \mathrm{~g}\right.$ a.i. acre $\left.^{-1}\right) /$ Puma super 75 FW @1.25 L ha ${ }^{-1}+$ Buctril super EC @ $750 \mathrm{ml} \mathrm{ha}^{-1}$ herbicide was sprayed with the help of knapsack sprayer to control broad and narrow leaf weeds to avoid weed crop competition.

\section{Data collection for crop duration parameters}

Data on crop duration parameters was collected using Zadok's Cereal Growth Stages key (Zadoks et al., 1974). These included days to emergence, jointing, booting, heading, anthesis and maturity. Data regard- ing days to emergence was recorded by counting the days taken from the date of sowing to the date when $75 \%$ emergence occurred in each plot. Data regarding days to jointing was recorded by counting the days taken from the date of sowing to the date when $75 \%$ plants reached the jointing stage in each plot. Days to booting were recorded by counting number of days taken from date of sowing to the date when $75 \%$ plants reached the boot stage in each plot. Days to heading were recorded by counting the days taken by crop from sowing until $75 \%$ plants reached the heading stage in each plot. Days to anthesis were recorded by counting the days from planting to the date when $75 \%$ plants reached the anthesis stage in each plot. Days to maturity were recorded by counting the number of days from sowing till $75 \%$ plants reached the physiological maturity in each plot indicated by yellow color of the spikes (Mohsin et al., 2012).

\section{Field testing of selected 108 Chinese wheat hybrids}

A subset of approximately 108 hybrids from the 416 Chinese wheat hybrids was selected and tested for crop duration parameters to assess the impact of selection and estimate selection differential and genetic advance. The performance of selected hybrids and commercial heterosis was also described in comparison with five promising local check varieties over two years (2017-18 and 2018-19).

For the field testing of the selected 108 Chinese wheat hybrids, the augmented design was applied with 8 blocks and 20 subplots ( 15 hybrids and 5 check varieties), except for the last block which contained 8 subplots consisting of 3 hybrids and 5 check varieties, which were included to calculate the error mean square and block effect, as per standard practice. The remaining crop husbandry was maintained as that in the preliminary field testing (described above). The data was collected on crop duration parameters i.e., days to emergence, jointing, booting, heading, anthesis and maturity as described above (Maqbool et al., 2010; Khan and Hassan, 2018).

\section{Data analyses for assessment of selection impact}

The collected data was subjected to analysis of variance (ANOVA), by using the model to determine whether the genotypic differences were significant for the characters under consideration. The distributions of overall population (416 Chinese hybrids) and selected hybrids (during 2017-18 and 2018-19) were represented as Boxplots, generated through 
Table 1: List of tested Chinese wheat hybrids and five local check varieties along with their distribution into cluster groups, based on crop duration parameters.

\begin{tabular}{|c|c|c|c|c|c|c|c|c|c|c|c|}
\hline S. No. & Genotype & Group $^{a}$ & S. No. & Genotype & Group & S. No. & Genotype & Group & S. No. & Genotype & Group \\
\hline 1 & 17BH001 & G4 & 106 & 17BH106 & G1 & 211 & 17BH211 & G1 & 316 & 17BH316 & G1 \\
\hline 2 & 17BH002 & G1 & 107 & 17BH107 & G4 & 212 & 17BH212 & G1 & 317 & 17BH317 & G4 \\
\hline 3 & 17BH003 & G1 & 108 & 17BH108 & G1 & 213 & 17ВH213 & G2 & 318 & 17ВН318 & G4 \\
\hline 4 & 17BH004 & G4 & 109 & 17BH109 & G2 & 214 & 17BH214 & G4 & 319 & 17ВH319 & G1 \\
\hline 5 & 17BH005 & G2 & 110 & 17BH110 & G1 & 215 & 17BH215 & G4 & 320 & 17ВН320 & G4 \\
\hline 6 & 17BH006 & G1 & 111 & 17BH111 & G2 & 216 & 17BH216 & G4 & 321 & 17BH321 & G4 \\
\hline 7 & 17BH007 & $\mathrm{G} 2$ & 112 & 17BH112 & G1 & 217 & 17BH217 & G1 & 322 & 17ВН322 & G1 \\
\hline 8 & 17BH008 & G1 & 113 & 17BH113 & G4 & 218 & 17BH218 & G2 & 323 & 17BH323 & G4 \\
\hline 9 & 17BH009 & G1 & 114 & 17BH114 & G4 & 219 & 17BH219 & G1 & 324 & 17BH324 & G4 \\
\hline 10 & 17BH010 & G2 & 115 & 17BH115 & G1 & 220 & 17BH220 & G4 & 325 & 17BH325 & G3 \\
\hline 11 & 17BH011 & G2 & 116 & 17BH116 & G2 & 221 & 17BH221 & G3 & 326 & 17BH326 & G1 \\
\hline 12 & 17BH012 & G1 & 117 & 17BH117 & G2 & 222 & 17BH222 & G3 & 327 & 17ВH327 & G1 \\
\hline 13 & 17BH013 & G2 & 118 & 17BH118 & G4 & 223 & 17BH223 & G4 & 328 & 17BH328 & G4 \\
\hline 14 & 17BH014 & G1 & 119 & 17BH119 & G4 & 224 & 17BH224 & G2 & 329 & 17BH329 & G4 \\
\hline 15 & 17BH015 & G2 & 120 & 17BH120 & G4 & 225 & 17BH225 & G4 & 330 & 17BH330 & G1 \\
\hline 16 & 17BH016 & G4 & 121 & 17BH121 & G4 & 226 & 17BH226 & G4 & 331 & 17BH331 & G4 \\
\hline 17 & 17BH017 & G1 & 122 & 17BH122 & G2 & 227 & 17BH227 & G4 & 332 & 17BH332 & G4 \\
\hline 18 & 17BH018 & G1 & 123 & 17BH123 & G2 & 228 & 17BH228 & G4 & 333 & 17BH333 & G2 \\
\hline 19 & 17BH019 & G4 & 124 & 17BH124 & G1 & 229 & 17BH229 & G1 & 334 & 17BH334 & G4 \\
\hline 20 & 17BH020 & G2 & 125 & 17BH125 & G4 & 230 & 17BH230 & G1 & 335 & 17BH335 & G4 \\
\hline 21 & 17BH021 & G1 & 126 & 17BH126 & G3 & 231 & 17BH231 & G1 & 336 & 17BH336 & G4 \\
\hline 22 & 17BH022 & G1 & 127 & 17BH127 & G4 & 232 & 17BH232 & G4 & 337 & 17BH337 & G4 \\
\hline 23 & 17BH023 & G1 & 128 & 17BH128 & G1 & 233 & 17BH233 & G3 & 338 & 17BH338 & G1 \\
\hline 24 & 17BH024 & G1 & 129 & 17BH129 & G2 & 234 & 17BH234 & G4 & 339 & 17BH339 & G4 \\
\hline 25 & 17BH025 & G4 & 130 & 17BH130 & G4 & 235 & 17BH235 & G1 & 340 & 17BH340 & G4 \\
\hline 26 & 17BH026 & G2 & 131 & 17BH131 & G2 & 236 & 17BH236 & G4 & 341 & 17BH342 & G4 \\
\hline 27 & 17BH027 & G1 & 132 & 17BH132 & G1 & 237 & 17BH237 & G4 & 342 & 17BH343 & G4 \\
\hline 28 & 17BH028 & G4 & 133 & 17BH133 & G1 & 238 & 17BH238 & G4 & 343 & 17BH344 & G3 \\
\hline 29 & 17BH029 & G1 & 134 & 17BH134 & G4 & 239 & 17BH239 & G4 & 344 & 17BH345 & G4 \\
\hline 30 & 17BH030 & G4 & 135 & 17BH135 & G1 & 240 & 17BH240 & G4 & 345 & 17BH346 & G1 \\
\hline 31 & 17BH031 & G1 & 136 & 17BH136 & G4 & 241 & 17BH241 & G4 & 346 & 17BH347 & G4 \\
\hline 32 & 17BH032 & G1 & 137 & 17BH137 & G1 & 242 & 17BH242 & G4 & 347 & 17BH348 & G4 \\
\hline 33 & 17BH033 & G2 & 138 & 17BH138 & G1 & 243 & 17BH243 & G3 & 348 & 17BH349 & G3 \\
\hline 34 & 17BH034 & G1 & 139 & 17BH139 & G1 & 244 & 17BH244 & G4 & 349 & 17ВH350 & G4 \\
\hline 35 & 17BH035 & G1 & 140 & 17BH140 & G4 & 245 & 17BH245 & G4 & 350 & 17BH351 & G3 \\
\hline 36 & 17BH036 & G2 & 141 & 17BH141 & G4 & 246 & 17BH246 & G4 & 351 & 17BH352 & G4 \\
\hline 37 & 17BH037 & G1 & 142 & 17BH142 & G4 & 247 & 17BH247 & G1 & 352 & 17BH353 & G4 \\
\hline 38 & 17BH038 & G1 & 143 & 17BH143 & G4 & 248 & 17BH248 & G4 & 353 & 17BH354 & G4 \\
\hline 39 & 17BH039 & G1 & 144 & 17BH144 & G4 & 249 & 17BH249 & G1 & 354 & 17BH355 & G4 \\
\hline 40 & 17BH040 & G1 & 145 & 17BH145 & G4 & 250 & 17BH250 & G1 & 355 & 17BH356 & G4 \\
\hline 41 & 17BH041 & G1 & 146 & 17BH146 & G4 & 251 & 17BH251 & G4 & 356 & 17BH357 & G3 \\
\hline 42 & 17BH042 & G2 & 147 & 17BH147 & G4 & 252 & 17BH252 & G4 & 357 & 17BH358 & G1 \\
\hline 43 & 17BH043 & G2 & 148 & 17BH148 & G2 & 253 & 17BH253 & G4 & 358 & 17BH359 & G1 \\
\hline 44 & 17BH044 & G2 & 149 & 17BH149 & G1 & 254 & 17BH254 & G4 & 359 & 17BH360 & G4 \\
\hline
\end{tabular}




\begin{tabular}{|c|c|c|c|c|c|c|c|c|c|c|c|}
\hline 45 & 17BH045 & G4 & 150 & 17BH150 & G4 & 255 & 17BH255 & G4 & 360 & 17BH361 & G4 \\
\hline 46 & 17BH046 & G1 & 151 & 17BH151 & G4 & 256 & 17BH256 & G4 & 361 & 17BH362 & G3 \\
\hline 47 & 17BH047 & G2 & 152 & 17BH152 & G4 & 257 & 17BH 257 & G4 & 362 & 17BH363 & G4 \\
\hline 48 & 17BH048 & G2 & 153 & 17BH153 & G4 & 258 & 17BH258 & G4 & 363 & 17BH364 & G4 \\
\hline 49 & 17BH049 & G2 & 154 & 17BH154 & G1 & 259 & $17 \mathrm{BH} 259$ & G4 & 364 & 17BH365 & G4 \\
\hline 50 & 17BH050 & G1 & 155 & 17BH155 & G2 & 260 & 17BH260 & G1 & 365 & 17BH366 & G4 \\
\hline 51 & 17BH051 & G1 & 156 & 17BH156 & G2 & 261 & 17BH261 & G4 & 366 & 17BH367 & G4 \\
\hline 52 & 17BH052 & G4 & 157 & 17BH157 & G4 & 262 & 17BH262 & G4 & 367 & 17ВН368 & G4 \\
\hline 53 & 17BH053 & G1 & 158 & 17BH158 & G4 & 263 & 17BH263 & G1 & 368 & 17BH369 & G4 \\
\hline 54 & 17BH054 & G2 & 159 & 17BH159 & G4 & 264 & 17BH264 & G4 & 369 & 17BH370 & G4 \\
\hline 55 & 17BH055 & G1 & 160 & 17BH160 & G1 & 265 & 17BH265 & G4 & 370 & 17ВН371 & G4 \\
\hline 56 & 17BH056 & G4 & 161 & 17BH161 & G1 & 266 & 17BH266 & G1 & 371 & 17ВH372 & G4 \\
\hline 57 & 17BH057 & G1 & 162 & 17BH162 & G2 & 267 & 17BH267 & G1 & 372 & 17BH373 & G4 \\
\hline 58 & 17BH058 & G1 & 163 & 17BH163 & G1 & 268 & 17BH268 & G4 & 373 & 17BH374 & G4 \\
\hline 59 & 17BH059 & G1 & 164 & 17BH164 & G4 & 269 & 17BH269 & G4 & 374 & 17ВН375 & G4 \\
\hline 60 & 17BH060 & G1 & 165 & 17BH165 & G4 & 270 & 17BH270 & G1 & 375 & 17BH376 & G1 \\
\hline 61 & 17BH061 & G1 & 166 & 17BH166 & G4 & 271 & 17BH271 & G4 & 376 & 17ВH377 & G1 \\
\hline 62 & 17BH062 & G1 & 167 & 17BH167 & G4 & 272 & 17BH272 & G4 & 377 & 17BH378 & G3 \\
\hline 63 & 17BH063 & G1 & 168 & 17BH168 & G4 & 273 & 17BH273 & G4 & 378 & 17ВН379 & G4 \\
\hline 64 & 17BH064 & G1 & 169 & 17BH169 & G1 & 274 & 17BH274 & G4 & 379 & 17BH380 & G3 \\
\hline 65 & 17BH065 & G1 & 170 & 17BH170 & G4 & 275 & 17BH275 & G4 & 380 & 17BH381 & G4 \\
\hline 66 & 17BH066 & G1 & 171 & 17BH171 & G4 & 276 & 17BH276 & G4 & 381 & 17ВH382 & G4 \\
\hline 67 & 17BH067 & G1 & 172 & 17BH172 & G1 & 277 & 17BH277 & G4 & 382 & 17BH383 & G4 \\
\hline 68 & 17BH068 & G1 & 173 & 17BH173 & G4 & 278 & 17BH278 & G4 & 383 & 17BH384 & G4 \\
\hline 69 & 17BH069 & G4 & 174 & 17BH174 & G1 & 279 & 17BH279 & G1 & 384 & 17ВH385 & G4 \\
\hline 70 & 17BH070 & G1 & 175 & 17BH175 & G4 & 280 & 17BH280 & G4 & 385 & 17ВH386 & G4 \\
\hline 71 & 17BH071 & G2 & 176 & 17BH176 & G4 & 281 & 17BH281 & G1 & 386 & 17BH387 & G4 \\
\hline 72 & 17BH072 & G2 & 177 & 17BH177 & G4 & 282 & 17BH282 & G4 & 387 & 17ВН388 & G3 \\
\hline 73 & 17BH073 & G1 & 178 & 17BH178 & G1 & 283 & 17BH283 & G4 & 388 & 17BH389 & G4 \\
\hline 74 & 17BH074 & G2 & 179 & 17BH179 & G1 & 284 & 17BH284 & G4 & 389 & 17ВH390 & G4 \\
\hline 75 & 17BH075 & G1 & 180 & 17BH180 & G4 & 285 & 17BH285 & G4 & 390 & 17ВH391 & G3 \\
\hline 76 & 17BH076 & G1 & 181 & 17BH181 & G4 & 286 & 17BH286 & G1 & 391 & 17BH392 & G3 \\
\hline 77 & 17BH077 & G1 & 182 & 17BH182 & G1 & 287 & 17BH287 & G3 & 392 & 17ВH393 & G4 \\
\hline 78 & 17BH078 & G1 & 183 & 17BH183 & G1 & 288 & 17BH288 & G1 & 393 & 17ВН394 & G3 \\
\hline 79 & 17BH079 & $\mathrm{G} 2$ & 184 & 17BH184 & G2 & 289 & 17BH289 & G4 & 394 & 17BH395 & G4 \\
\hline 80 & 17BH080 & G1 & 185 & 17BH185 & G1 & 290 & 17BH290 & G4 & 395 & 17BH396 & G4 \\
\hline 81 & 17BH081 & G1 & 186 & 17BH186 & G4 & 291 & 17BH291 & G4 & 396 & 17BH397 & G4 \\
\hline 82 & 17BH082 & G4 & 187 & 17BH187 & G3 & 292 & 17BH292 & G4 & 397 & 17BH398 & G3 \\
\hline 83 & 17BH083 & $\mathrm{G} 2$ & 188 & 17BH188 & G4 & 293 & 17BH293 & G2 & 398 & 17ВН399 & G3 \\
\hline 84 & 17BH084 & G2 & 189 & 17BH189 & G4 & 294 & 17BH294 & G1 & 399 & $17 \mathrm{BH} 400$ & G4 \\
\hline 85 & 17BH085 & G1 & 190 & 17BH190 & G1 & 295 & 17BH295 & G4 & 400 & 17BH401 & G3 \\
\hline 86 & 17BH086 & G4 & 191 & 17BH191 & G2 & 296 & 17BH296 & G4 & 401 & 17BH402 & G4 \\
\hline 87 & 17BH087 & G1 & 192 & 17BH192 & G1 & 297 & 17BH297 & G4 & 402 & 17BH403 & G4 \\
\hline 88 & 17BH088 & G4 & 193 & 17BH193 & G4 & 298 & 17BH298 & G1 & 403 & 17BH404 & G4 \\
\hline 89 & 17BH089 & G4 & 194 & 17BH194 & G1 & 299 & 17BH299 & G4 & 404 & 17BH405 & G4 \\
\hline 90 & 17BH090 & G1 & 195 & 17BH195 & G4 & 300 & 17BH300 & G4 & 405 & 17BH406 & G4 \\
\hline 91 & 17BH091 & G1 & 196 & 17BH196 & G1 & 301 & 17ВН301 & G4 & 406 & 17BH407 & G1 \\
\hline
\end{tabular}




\begin{tabular}{|c|c|c|c|c|c|c|c|c|c|c|c|}
\hline 92 & 17BH092 & G1 & 197 & 17BH197 & G4 & 302 & 17BH302 & G4 & 407 & 17BH408 & G4 \\
\hline 93 & 17BH093 & G4 & 198 & 17BH198 & G2 & 303 & 17BH303 & G4 & 408 & 17BH409 & G4 \\
\hline 94 & 17BH094 & G4 & 199 & 17BH199 & G4 & 304 & 17BH304 & G3 & 409 & 17BH410 & G4 \\
\hline 95 & 17BH095 & G1 & 200 & 17BH200 & G4 & 305 & 17BH305 & G1 & 410 & 17BH411 & G4 \\
\hline 96 & 17BH096 & G1 & 201 & 17BH201 & G4 & 306 & 17BH306 & G1 & 411 & 17BH412 & G4 \\
\hline 97 & 17BH097 & G1 & 202 & 17BH202 & G4 & 307 & 17BH307 & G4 & 412 & 17BH413 & G4 \\
\hline 98 & 17BH098 & G1 & 203 & 17BH203 & G2 & 308 & 17BH308 & G4 & 413 & 17BH414 & G4 \\
\hline 99 & 17BH099 & G4 & 204 & 17BH204 & G4 & 309 & 17ВН309 & G4 & 414 & 17BH415 & G4 \\
\hline 100 & 17BH100 & G2 & 205 & 17BH205 & G1 & 310 & 17BH310 & G4 & 415 & 17BH416 & G4 \\
\hline 101 & 17BH101 & G1 & 206 & 17BH206 & G1 & 311 & 17BH311 & G3 & 416 & 17BH417 & G4 \\
\hline 102 & 17BH102 & G4 & 207 & 17BH207 & G4 & 312 & 17ВН312 & G4 & \multirow[t]{3}{*}{3 Local checks } & \multirow{3}{*}{$\begin{array}{l}\text { Ghanimat- } \\
\text { e-IBGE, Shah- } \\
\text { kar-13, PS-13 }\end{array}$} & \multirow[t]{3}{*}{ G3 } \\
\hline 103 & 17BH103 & G3 & 208 & 17BH208 & G4 & 313 & 17BH313 & G1 & & & \\
\hline 104 & 17BH104 & G4 & 209 & 17BH209 & G4 & 314 & 17BH314 & G4 & & & \\
\hline 105 & 17BH105 & G2 & 210 & 17BH210 & G1 & 315 & 17BH315 & G1 & 2 Local checks & $\begin{array}{l}\text { PS-15 \& At- } \\
\text { ta-Habib }\end{array}$ & G4 \\
\hline
\end{tabular}

Note: ${ }^{a}$ refers to clustering group assigned based on crop duration parameters.

Table 2: Mean square values and their significance for various crop duration parameters tested during 2017-18.

\begin{tabular}{llllllllllll} 
Studied Parameter & \multicolumn{4}{l}{ Mean square values } & \multicolumn{4}{l}{ Hybrid vs. check } & Among Checks & Among hybrids \\
& \multicolumn{2}{l}{ Check varieties } & \multicolumn{2}{l}{ Hybrids } & \multicolumn{2}{l}{ Hon (0.05) values } \\
Days to emergence & 6.57 & NS & 2.06 & NS & 20.86 & $* *$ & NS & NS \\
Days to jointing & 86.93 & $*$ & 47.98 & $* *$ & 50.96 & NS & 2.99 & 14.93 \\
Days to booting & 101.49 & $* *$ & 25.45 & $*$ & 249.49 & $* *$ & 2.42 & 12.10 \\
Days to heading & 131.34 & $* *$ & 13 & $*$ & 25 & NS & 1.76 & 8.8 \\
Days to anthesis & 83 & NS & 8 & NS & 425 & $* *$ & NA & NA \\
Days to maturity & 10 & NS & 4 & NS & 1 & NS & NA & NA \\
Degree of freedom & 4 & & 415 & & 1 & & 4 & 415
\end{tabular}

Note: *refers to significance at less than 5\%, *' refers to significance at less than 1\%; NS refers to "non-significant".

$\mathrm{R}$-statistical software, to assess the role of selection in changing the distribution of these parameters. Selection differential and genetic advance was estimated through comparing the difference in performance of overall population and selected hybrids during the same year (for selection differential) and over the subsequent year (for genetic advance).

\section{Results and Discussion}

Our results revealed a highly significant variability among the tested wheat hybrids for various crop duration parameters (Table 1), revealing a very high and significant variability among the Chinese hybrids, reflected by the mean square values and their significance. The selected hybrids performance showed significant variability, with better performance for certain hybrids than the local checks. This variability in performance was further confirmed by the subsequent year performance of the selected hybrids. The work enabled to identify the hybrids with better performance than local checks.

\section{Preliminary assessment of 416 Chinese wheat hybrids for crop duration parameter}

During the preliminary testing of 416 Chinese hybrids, the differences for days to emergence were non-significant between varieties and hybrids, while these were significant for hybrids versus varieties ( $\mathrm{Ta}-$ ble 2). Significant differences were observed for days to jointing between hybrids (LSD: 14.93) and between varieties (LSD: 2.99). However, no significant differences were found between varieties vs. hybrids. Significant differences for days to booting between hybrids (LSD: 12.10), varieties (LSD: 2.42) and hybrids vs varieties were observed. Significant differences were observed for the hybrids (LSD: 8.8) and varieties (LSD: 1.76) for days to booting. The mean square values revealed higher variability among the hybrids compared to the local checks. The analysis of December 2021 | Volume 37 | Issue 4 | Page 1183 
variance for the days to anthesis revealed non-significant results for both, the hybrids and check varieties, whereas the hybrid vs. check probability was shown to be significant. The days to maturity showed non-significant results for all, hybrids, varieties and hybrids versus check varieties. The Chinese hybrids exhibited higher diversity compared to the local checks (Figure $1)$.

The days to emergence for the Chinese hybrids ranged from 10 to 15 , with a mean value of 12 and standard deviation of 1.44 (Figure 1a). This range included the range for days to emergence of the local check varieties, which ranged from 11 days (for Ghanimat-e-IBGE) to 13 days (observed for Shahkar-13 and Atta-Habib) with a mean value of 12 and standard deviation of 0.84 . The values mentioned clearly indicated that the hybrids had higher variability than the local checks and could be exploited for subsequent selection.

The genetic diversity in terms of days to jointing was assessed for Chinese hybrids and local checks, as plotted through the boxplots. The boxplots clearly indicated greater variations of the hybrids against the check varieties (Figure 1b). The days to jointing for the hybrids ranged between 50 and 73 , with a mean value of 62 and S.D of 6.93. The range for the hybrids included even the range of the check varieties which was 60 (observed for Ghanimat-e-IBGE) to 65 (observed for Atta Habib) with mean value of 62 and S.D of 1.82. These values clearly hint towards higher variability of the hybrids compared to the local checks.

The days to booting also exhibited higher diversity in the Chinese hybrids than the local checks (Figure 1c). The range of days to booting between the hybrids was 82 to 100 with a mean value of 93 and standard deviation of 5.05. The values for the days to booting among the check varieties were 89 (recorded for PirSabak-15) to 94 (recorded for Atta Habib) which was included in the range of the hybrids. The mean value for the checks was 91 with standard deviation of 1.92 . This showed higher diversity in the hybrids opposing to the checks.

Days to heading for both, the hybrids and the checks, were recorded for assessing the genetic diversity for crop duration, considering the importance of this parameter to crop production (Figure 1d). The values for the days to heading for the hybrids ranged between 102-118 with a mean value of 110 and standard deviation of 3.64. These values included the values of the local checks which ranged between 107 (observed for PirSabak-15) and 113 (observed for Atta Habib) with a mean value of 109 and S.D. of 2.30. The higher variation for days to heading for the hybrids than local checks could be useful for further selection.

The hybrids had larger range of the days to anthesis values between 119 and 130 with mean value of 124 and standard deviation of 2.80 (Figure 1e). The values for the checks ranged between 121 (observed for Ghanimat-e-IBGE, PirSabak-13 and PirSabak-15) to 125 (observed for Atta Habib) with mean value of 122 and standard deviation of 1.79 . The values clearly indicated higher variability of the Chinese hybrids compared to the local checks.

Genetic diversity for days to maturity was assessed for the 416 hybrids along with the check varieties, where the values ranged between 151 and 159 with a mean value of 154 and S.D of 1.90 for hybrids (Figure 1f). This revealed higher variability compared to the values of the check varieties, which ranged between 153 (recorded for Shahkar-13) and 155 (observed for PirSabak-15 and Atta Habib) having mean of 154 and S.D of 0.84 .

\section{Clustering of 416 Chinese wheat hybrids based on field parameters}

The clustering of 416 Chinese wheat hybrids in the preliminary assessment for crop duration parameters, grouped these into four major clusters, which could be subdivided to further sub-groups (Figure 2). Group G1 contained 118 Chinese hybrids, while group G2 contained 136 Chinese hybrids. Group G3 and group G4 contained 102 and 63 Chinese hybrids, respectively. Group G2 could be said to have maximum hybrids for crop duration parameters.

The hybrids of group G1 took maximum number of days to emerge as evident from the clustering figure. Maximum number of days to jointing, booting, heading, anthesis and maturity were taken by the lines present in clustering group G2, thus, representing the group with long crop duration parameters among the tested lines. 

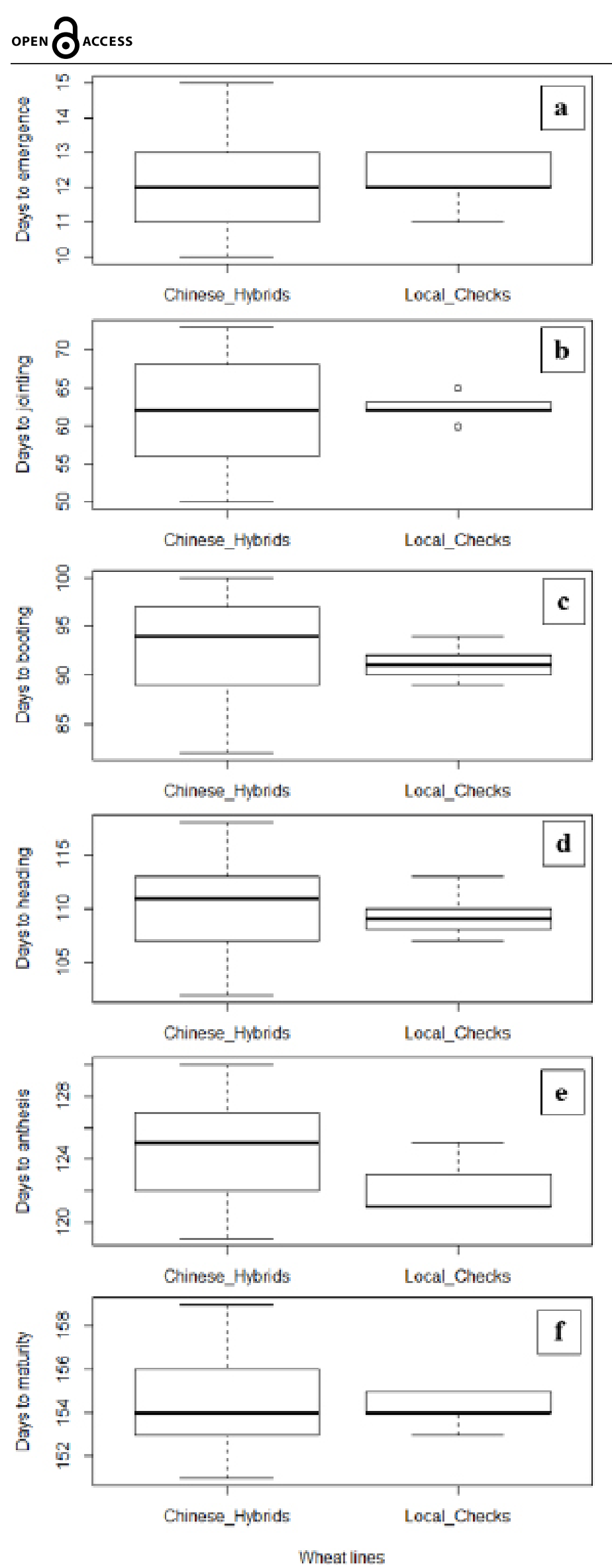

Figure 1: Diversity for crop duration parameters in a set of $416 \mathrm{ex}-$ otic Chinese hybrid lines, tested during 2017-18.

Impact of selection and estimation of selection differential A subset of 108 wheat hybrids was selected from these 416 Chinese wheat hybrids to estimate the selection

differential and genetic advance, in terms of the performance of selected hybrids over the second year. An overall high diversity was observed among the selected genotypes and the impact of selection was positive on almost all the studied parameters as reflected by the mean value, while the level of variation decreased as revealed by the standard deviation values (Table 4).

Field testing of selected 108 hybrids during 2018-19, revealed varying level of differences between varieties, hybrids and hybrids versus varieties which were found to be non-significant for days to emergence (Table 3). The analysis of variance for days to emergence revealed non-significant differences for hybrids, check varieties and hybrids vs check varieties. Hence, the variability for the hybrids was low. Days to jointing revealed highly significant differences between hybrids (LSD: 6.98) and check varieties (LSD: 2.47). The significant differences between hybrids revealed the higher variability between the hybrids. The hybrids vs check varieties also had significant differences. The analysis of variance for the days to booting revealed highly significant differences between hybrids (LSD: 5.5) and the local check varieties (LSD: 1.94). The hybrid vs check varieties also showed significant variation. This showed high variability among the hybrids. When subjected to analysis of variance for measuring the variation, the hybrids showed high level of significance (LSD: 6.76), along with check varieties (LSD: 2.39) for days to heading. Likewise, the hybrids vs check varieties also had significant differences. The variability for days to maturity between hybrids and varieties was lower as evident from the analysis of variance which revealed non-significant differences between hybrids and checks, while the differences were significant for hybrids vs. check varieties.

For the crop duration parameters, selection resulted in an overall increase in the mean value for crop duration, though an overall decrease in the variability $(\mathrm{Ta}-$ ble 4). The mean value for days to emergence was the same among the overall population, selected hybrids and the progeny of selected hybrids (12), while the standard deviations were 1.41, 1.47 and 1.22, respectively. The mean value for days to jointing increased from 62 in the overall population to 63 in selected hybrids and 69 in the progeny of the selected hybrids, while the standard deviation decreased from 6.98 to 6.56 and 3.14, respectively. There was also an increase in days to booting from 93 in the overall population and selected hybrids to 106 in the progeny of the se- 
lected



Figure 2: Clustering of 416 Chinese wheat hybrids and local check varieties based on various field characteristics. The information on various lines is given in Table 1.

Table 3: Mean square values and their significance for various crop duration parameters for the selected hybrids tested during 2018-19.

\begin{tabular}{llllllllll} 
Studied Parameter & \multicolumn{4}{l}{ Mean square values } & \multicolumn{4}{c}{ LSD (0.05) values } \\
& \multicolumn{2}{l}{ Hybrids } & \multicolumn{2}{l}{ Check varieties } & \multicolumn{2}{l}{ Hybrid vs. check } & Among hybrids & Among checks \\
Days to emergence & 5.615 & NS & 1.511 & NS & 0.158 & NS & NS & NS \\
Days to jointing & 16.51 & $*$ & 9.86 & $*$ & 194.00 & $* *$ & 2.47 & 6.98 \\
Days to booting & 36 & $* *$ & 6 & $*$ & 396 & $* *$ & 1.94 & 5.5 \\
Days to heading & 65 & $* *$ & 10 & $*$ & 455 & $* *$ & 2.39 & 6.76 \\
Days to anthesis & 37 & $* *$ & 4 & $*$ & 296 & $* *$ & 1.59 & 4.49 \\
Days to maturity & 18 & NS & 2 & NS & 181 & $* *$ & NS & NS
\end{tabular}

Note: "refers to significance at less than 5\%," refers to significance at less than 1\%; NS refers to "non-significant".

hybrids, though the standard deviation decreased from 5.03 to 5.01 and 2.59 , respectively. The days to heading increased from 110 in the overall populations and selected hybrids to 124 for the progeny of the selected hybrids; while the standard deviation decreased from 3.71 to 3.40 and 3.25 , respectively. The days to anthesis increased from 124 in the overall populations and selected hybrids to 137 for the progeny of the selected hybrids; while the standard deviation decreased from 2.86 to 2.66 and 2.11, respectively. For the last and most important crop duration parameter, days to maturity, the mean value increased from 154 in the overall population and selected hybrids to 164 in the progeny population, whereas the standard deviation was reduced from 1.95 to 1.73 and 1.66 , respectively.

\section{Distribution of crop duration parameters post-selection} The distribution of crop duration parameters was plotted as boxplots for overall population, the selected hybrids during 2017-18 and the second year (2018-
19) performance of the selected hybrids, to assess how the selection has influenced these parameters. The changes in distribution of crop duration parameters i.e., days to emergence, days to jointing, days to booting, days to heading, days to anthesis and days to maturity are shown in the boxplots (Figure 3). There was a decrease for all of the six crop duration parameters in the selected hybrids during 2017-18, though an overall increase was observed for the selected hybrids during the subsequent year (2018-19).

Days to emergence ranged from 10 days to 15 days in the overall population and the selected hybrids during 2018-19, though it was in the range of 10 days to 14 days for the selected hybrids, the same as that of the year 2017-18 (Figure 3a). There were no substantial changes in the distribution of days to emergence due to selection with a mean value of 12 days in all the populations, with limited impact on the variability (Table 4). 
Table 4: Descriptive parameters for the overall 416 Chinese wheat hybrids population, the selected hybrids and the progeny of selected hybrids.

\begin{tabular}{llllllll} 
Studied Parameter & \multicolumn{2}{l}{ Overall population } & \multicolumn{2}{l}{ Selected hybrids (2017-18) } & \multicolumn{2}{c}{ Selected hybrids (2018-19) } \\
& Mean & Standard Deviation & Mean & Standard Deviation & Mean & Standard Deviation \\
Days to emergence & 12 & 1.41 & 12 & 1.47 & 12 & 1.22 \\
Days to jointing & 62 & 6.98 & 63 & 6.56 & 69 & 3.14 \\
Days to booting & 93 & 5.03 & 93 & 5.01 & 106 & 2.59 \\
Days to heading & 110 & 3.71 & 110 & 3.40 & 124 & 3.25 \\
Days to anthesis & 124 & 2.86 & 124 & 2.66 & 137 & 2.11 \\
Days to maturity & 154 & 1.95 & 154 & 1.73 & 164 & 1.66
\end{tabular}

\section{Crop duration parameters}
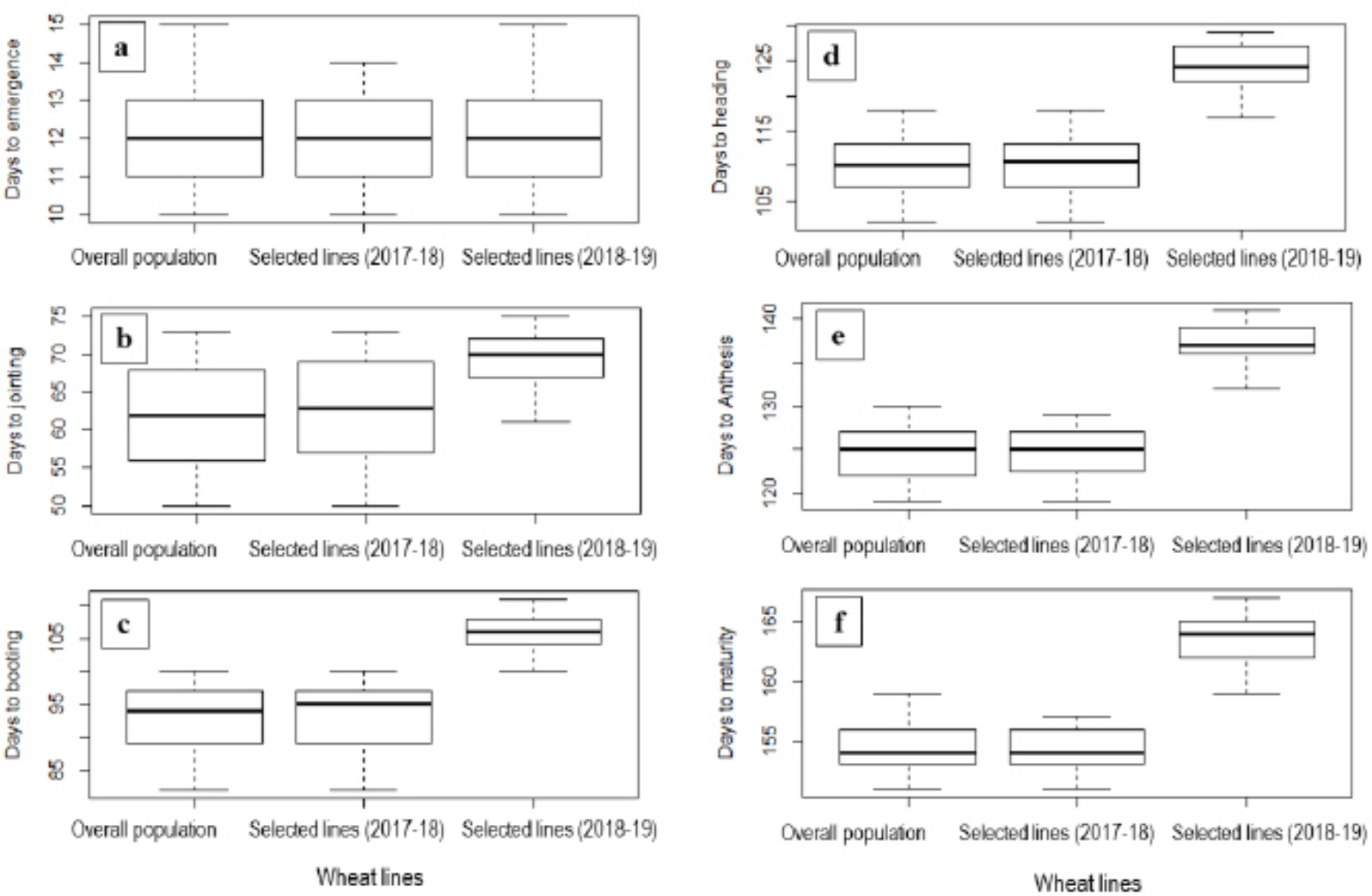

Figure 3: Distribution of crop duration parameters for various set of Chinese wheat hybrids as subjected to selection. The upper line represents the maximum, the lower line represents the minimum, which the middle bold line represents the average values. The dots represent the outlier values, if any.

Days to jointing was clearly impacted by the selection, as the data ranged from 50 days to 73 days in the overall population and selected hybrids during same year (2017-18), while it was shifted upward with a range of 61 days to 75 days in the subsequent year (2018-19) performance of the selected hybrids (Figure $3 \mathrm{~b}$ ). The mean value also shifted upward from 62 days (in the overall population) and 63 days (in the selected hybrids) to 69 days (in the subsequent year (2018-19)) performance of the selected hybrids (Table 4).
Selection from the overall population had a clear impact on days to booting (Figure 3c). Its range was 83100 for the overall population, with a mean value of 93 and 82-100 for the selected hybrids, with a mean value of 93 . The values substantially increased for the subsequent year (2018-19) performance of the selected hybrids, which were 100-111, with a mean of 106 .

Days to heading was the same for the both, the overall population and the selected hybrids. The values for overall population ranged from $102-117$, with mean 
of 110 (Figure $3 \mathrm{~d}$ ). The range of the selected hybrids was $102-118$, with a mean of 110 . The performance of the selected hybrids during the subsequent year (2018-19) clearly improved in that the values for the days to heading for the subsequent year (2018-19) performance of selected hybrids were 117-129 with a mean of 124 .

Both the overall population and the selected hybrids shared the same range for the days to anthesis,i.e., 119130 and 119-129, respectively, along with same mean value of 124 , for both, the overall population and selected hybrids (Figure 3e). The subsequent year (201819) performance of the selected hybrids, on the other hand, showed much elevated and improved performance with a range of 132-141 and mean value of 137 .

Just like the other crop duration parameters, the days to maturity was increasingly impacted in the subsequent year (2018-19) performance of the selected hybrids (range=159-167 and mean=164) compared to the overall population (range=151-159) and selected hybrids during the same (2017-18) year (range=151-157), both of which also shared the same mean of 154, revealing increase in crop duration (Figure 3f).

\section{Estimation of selection differential and genetic advance}

Selection differential and genetic advance (in terms of the $2^{\text {nd }}$ year performance of the selected hybrids) were estimated to assess the impact of selection on the exotic Chinese wheat hybrids which revealed an overall improvement in various parameters in desired direction (Figure 4). Among the crop duration parameters, maximum selection differential was observed for the days to jointing which was 2.25 and minimum of -0.03 for days to maturity. The maximum genetic advance was observed for the days to heading which was 12.89 whereas it was minimum for days to emergence which was 4.86 .

The present study revealed a high diversity among Chinese hybrids for various characteristics, which enabled to carry out selection with subsequent testing of the selected hybrids. These hybrids were engineered at Beijing Engineering Research Centre for Hybrid Wheat (BERCHW), China, representing a novel source of germplasm, not previously tested in Pakistan. Efficient germplasm management and genotype selection is very useful for different breeding purposes (Fufa et al., 2005). The genetic variations between individuals in a population is the genetic variability which could be the heart of plant breeding as diversity management can yield permanent gain in plant production and protect against climatic changes. The limited gain achieved in yield across various wheat growing regions have been shown to be associated with the limited variability in wheat germplasm unable to overcome the pathogen changing races and limited consideration of crop duration parameters (Ali et al., 2017; Ray et al., 2013). This necessitates to widen the sources of crop germplasm and testing the non-traditional sources. Our results revealed a highly significant variability among the tested wheat hybrids for crop duration parameters. The preliminary trial revealed better performance of certain hybrids when compared with the recently recommended best performing Pakistani wheat check varieties. Performance of the selected lines revealed the impact of selection exerted on the 416 hybrids in terms of change in distribution and estimation of selection differential and genetic advance.
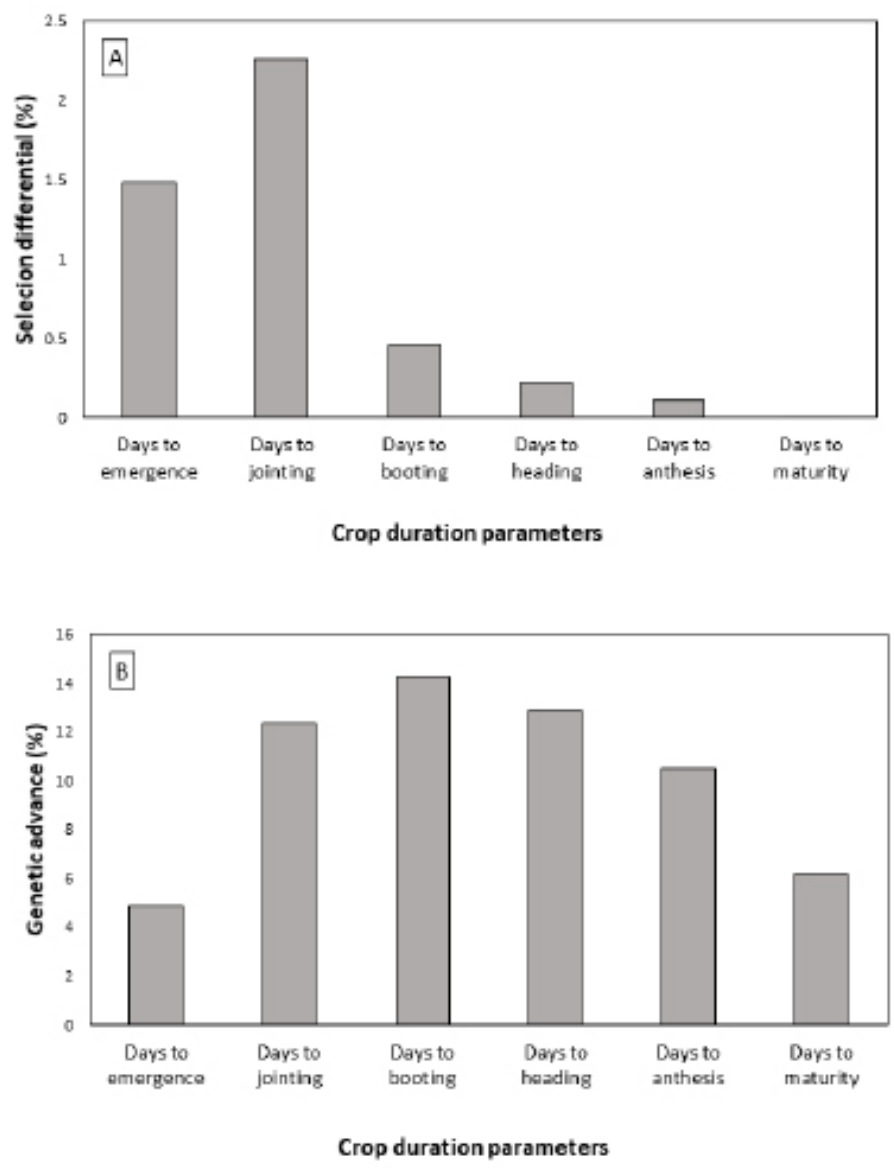

Figure 4: Impact of selection in a set of 416 Chinese wheat bybrids, as assessed by selection differential ( $A)$ and genetic advance (B).

Preliminary testing of the Chinese hybrids during the first experiment revealed a wide range of variability in all parameters in comparison with the improved local 
checks i.e., Shahkar, Pirsabak-2013, Pirsabak-2015, Atta-Habib and Ghanimat-e-IBGE, which are widely grown better performing wheat varieties (Khan et al., 2020a). The performance of a hybrid may vary when introduced into a novel area and thus, testing of exotic germplasm is a pre-requisite for further breeding (Qasim et al., 2008). Preliminary testing is the first step in many field crops like wheat to characterize a large set of germplasm for subsequent selection (Fufa et al., 2005; Perween et al., 2020). The effectiveness of the selection for both quantitative and qualitative traits depend on the genetic variability and heritability (Khan and Hassan, 2018). Field based preliminary testing in various parameters is essential in order to quantify the phenotypic variation for the prediction of genetic gain (Aycicek and Yildirim 2006).

The information in the preliminary trial is not only important for selection of parents with better performance to be crossed, but is also important for selection of better performing $\mathrm{F}_{1}$ hybrids, particularly while introducing exotic hybrids, as in the current case. Such studies could also provide information on the useful genes in the rich allelic stock of hybrids, which have been developed from Chinese landraces and wheat cultivars (Peleg et al., 2009; Dresselhaus and Hückelhoven 2018). Better performance was shown by hybrid varieties in many crops including maize (Duvick 1997; Li et al., 2013).

Looking at the crop duration characters in the preliminary testing, hybrids were proven to provide substantial diversity both for early and late maturing lines, when compared with the local high yielding and better performing varieties. The growth rate, reflected by the crop duration parameters, during the period from emergence to the grain filling is the crucial period for determining the overall yield potential in wheat (Dreccer et al., 2018). For maximum yield and stability, the time of heading, among the phenological stages of wheat plant, is crucial (Raza et al., 2018). For optimum utilization of the genetic material for plant breeding and associated procedures, consideration of crop duration parameters is important (Uddin and Boerner 2008).

The overall grouping of the 416 Chinese hybrids based on the field-based parameters recorded during the preliminary testing revealed the existence of very high diversity. The clustering analyses have been shown to be very useful for assessing diversity and grouping of variability based on phenotypic traits (Ali et al., 2009). Clustering based on important agronomic and primary traits would account for subsequent selection (Nepolean et al., 2018). The exotic genotypes under study needs to be exposed to different agro-ecological conditions, which may lead to different performance of various genetic parameters and their knowledge could help to decide breeding strategies. Field based screening with subsequent selection for the required traits in different genetic stocks is the preconditions for improving wheat. Various phenotypic and physiological traits are being studied as selection objectives for wheat breeding programs (Casadesús et al., 2007; Naghavi et al., 2007). Phenotypic performance can be based for criteria of selection of the parents. Additionally, the genotype into environment interaction results in determining the phenotype of an individual. The resultant phenotype may be due to environmental conditions which may vary at different locations (Najaphy et al., 2012). Development of better varieties and selection with better chances result from high genetic diversity which could be evaluated utilizing pedigree analysis, morphological and physiological characters and molecular markers (Habash et al., 2009).

Selection of a subset of 108 promising wheat hybrids from these 416 Chinese wheat hybrids showed a clear impact of selection on the distribution of crop duration parameters, with an overall decrease in standard deviation values, which revealed declining variation among the selected hybrids. Considering the performance of the selected Chinese hybrids tested during 2017-18 and 2018-19, a high variability and better performance for various parameters was observed, when compared with the most promising local wheat cultivars. High genetic advance as percent of mean for days to heading, grain filling period, whereas moderate genetic advance as percent of mean for days to maturity was reported by Demelash et al. (2013). The distribution of the overall hybrids compared to the selected hybrids during the same year and the subsequent year varied significantly. This was further evident by selection differential and genetic advance. The genetic advance here should be considered carefully as the progeny of the selected hybrids is not the $\mathrm{F}_{2}$ progeny of the $\mathrm{F}_{1}$ hybrids, but merely the second-year testing of selected hybrids. It is important to point out that the selection gain in hybrids must be higher compared to line breeding, in terms of yield, its stability and biotic and abiotic resistance to stress to overcome the as- 
sociated cost of hybrid breeding (Mette et al., 2015). The distribution of crop duration parameters (days to emergence, jointing, booting, heading, anthesis and maturity) revealed an overall increase due to selection. The variation, on the other hand, was comparatively lower among the crop duration parameters especially for days to jointing and booting where it decreased by two folds. Considering the performance of selected hybrids in terms of crop duration/crop duration $\mathrm{pa}^{-}$ rameters, 65 hybrids (both years combined) were earlier than the local checks, while 67 hybrids were late than the latest local check. This emphasized that a few elite hybrids could be selected from these selected 108 Chinese hybrids. The crop duration parameters are important for attaining better crop yield, as both early crop duration and delayed crop duration have their pros and cons (Dreccer et al., 2018).

Crop duration would ensure a short duration of crop in wheat, avoiding terminal heat stress and enable a timely sowing of the next crop (Raza et al., 2018). A longer crop duration would provide more degree days for production and accumulation of photosynthates in the grain, resulting in a higher grain yield. A longer duration could also be useful in context of dual-purpose wheat providing both, fodder and grain yields (Arif et al., 2006; Naveed et al., 2015). The variability in the Chinese germplasm could provide, both, short and long duration wheat hybrids. The reduction in yield due to radiation levels lower than optimum and damage to reproductive parts resulting from frost prevents flowering in winter (Dreccer et al., 2018). Late flowering due to warm and dry conditions can result in water scarcity and damage by heat and ultimately, result in reduced yield (Flohr et al., 2017). Winter hardiness and plant morphology is essential for adaptation, among other significant aspects of development, which should be paralleled with seasonal development. Crop breeding strategies can be improved by having thorough knowledge about the genetic base of crop duration characters which can even add to prediction of risks related to yield, like drought, frost and heat (Dreccer et al., 2018).

This work is one of the few studies to characterize the Chinese hybrid wheat lines in Pakistan. Better performance and adaptability to diverse conditions and environments have been shown as characteristics of hybrid wheat (Lang, 1989). However, hybrid production is quite complicated due to its flowering characteristics and large and hexaploid wheat genome, yet its potential is considered as one of the promising avenue for commercial exploitation of hybrid vigor for increasing wheat productivity (Reynolds et al., 1996). A larger extent of exchange of genetic material was required for extracting transgressive segregants from crosses among complementary parents for breeding pure line cultivars in self-pollinated crops (Heisey et al., 2002). The acceptability of cross-pollinated traits along with the male sterility introduction have been shown to possess a potential for hybrid wheat development (Pickett, 1993). The hybrids studied in the current study are based on the male sterility traits, and considering their Chinese origin, these are well suited to be considered under Pakistani wheat production system.

Observed variability in the Chinese hybrids could be utilized as additional diversity in wheat germplasm. A direct exploitation of our results would be to further test and release the promising Hybrids in Pakistan. However, the hybrids need evaluation and examination at different levels for multiple years in order to properly evaluate their feasibility, while considering the limitation of the cost of hybrid production. Crossing these hybrids with local lines could also diversify the germplasm of wheat. Varieties and lines need to be further evaluated for resistance to all the rusts specifically yellow and leaf rust (Ali and Hodson, 2017).

\section{Conclusions and Recommendations}

The current study revealed a high diversity among Chinese hybrids, an overall positive impact of selection along with the identification of desirable hybrids based on two-year performance. The hybrids possessed high variability and even better performance than local checks in some cases. There is a huge potential for exploitation of wheat hybrid in Pakistan, subject to subsequent testing in multilocation trials and farmer fields. The Chinese hybrids showed higher variation than the check varieties. The better performing hybrids during preliminary testing and second year testing "should undergo proper testing in national testing system". Various group of hybrids identified through boxplots and cluster analyses could be used in crossing blocks for resistance and high yield to diversify the germplasm of wheat.

\section{Acknowledgements}

The work was mainly supported by Pakistan Science 
Foundation research project and partly received support from the U.S. Department of Agriculture, Agricultural Research Service, under agreement No. 580206-0-171 F (Wheat Productivity Enhancement Program- WPEP) and Start-up Research Grant, Higher Education Commission, Pakistan. We would like to acknowledge our Chinese collaborators and field staff for their support.

\section{Novelty statement}

The work is the first-ever attempt to assess the impact of selection on variability in crop duration parameters for Chinese hybrids under the field conditions. The work is one of the few studies to explore the potential of Chinese wheat hybrids in Pakistan, which should contribute to improvement of wheat production in Pakistan.

\section{Authors' contribution}

MA and SA designed the study. ZI, MA and SA conducted the study and analyzed the data. MA, IM and SA provided resources for the study. ZA, IM, MA and SA wrote and revised the manuscript.

\section{References}

Ali, S. and D. Hodson. 2017a. Wheat rust surveillance; field disease scoring and sample collection for phenotyping and molecular genotyping. In: Methods in Molecular Biology (ed. Periyannan S). Humana Press. https://doi. org/10.1007/978-1-4939-7249-4_1

Ali, S., J. Rodriguez-Algaba, T. Thach, C. Sørensen, J.G. Hansen, P. Lassen, D. Hodson, K. Nazari, A.F. Justesen and M.S. Hovmøller. 2017b. Yellow rust epidemics worldwide were caused by pathogen races from divergent genetic lineages. Front. Plant Sci. 8: 1058. https://doi. org/10.3389/fpls.2017.01057

Ali, S., P. Gladieux, H. Rahman, M.S. Saqib, M.Leconte, J. Enjalbert and C. de Vallavieille-Pope. 2014c. A high virulence and pathotypes diversity of Puccinia striiformis $\mathrm{f}$. sp. tritici at its center of diversity, the Himalayan region of Pakistan. Eur. J. Plant Pathol. 140(2): 275-290 https:// doi.org/10.1007/s10658-014-0461-2

Ali, S., P. Gladieux, M. Leconte, A. Gautier, A.F. Justesen, M.S. Hovmøller, J. Enjalbert, and C. de Vallavieille-Pope. 2014a. Origin, Migration
Routes and Worldwide Population Genetic Structure of the Wheat Yellow Rust Pathogen Puccinia striiformis f.sp. tritici. PLoS Pathog. 10(1): e1003903. https://doi.org/10.1371/journal.ppat.1003903

Ali, S., S. J.A. Shah, I.H. Khalil, H. Rahman, K. Maqbool and W. Ullah. 2009. Partial resistance to yellow rust in introduced winter wheat germplasm at the north of Pakistan. Aust. J. Crop Sci. 3(1): 37-43.

Arif, M., M.A. Khan, H. Akbar, M. Sajjad and S. Ali. 2006. Prospects of wheat as a dual-purpose crop and its impact on weeds. Pak. J. Weed Sci. Res. 12: 13-18.

Aycicek, M. and T. Yildirim. 2006. Heritability of yield and some yield components in bread wheat (Triticum aestivum L.) genotypes. Bangladesh J. Bot. 35(1): 17-22.

Casadesús, J., Y. Kaya, J. Bort, M.M. Nachit, J.L. Araus, S. Amor and H. Ouabbou. 2007. Using vegetation indices derived from conventional digital cameras as selection criteria for wheat breeding in water-limited environments. Ann. Appl.Bio. 150(2):227-236.https:// doi.org/10.1111/j.1744-7348.2007.00116.x

Demelash, A.L., T. Desalegn and G. Alemayehu. 2013. Genetic variation of bread wheat (Triticum aestivum L.) genotypes based on number of phenological and morphological traits at Marwold Kebele, WombermaWoreda, West Gojam. Wudpecker. Wudpecker J. Agric. Res. 2(6): 160166.

Dreccer, M.F., J. Fainges, J. Whish, F.C. Ogbonnaya and V.O. Sadras. 2018. Comparison of sensitive stages of wheat, barley, canola, chickpea Phenology and related traits for wheat adaptation and field pea to temperature and water stress across Australia. Agric. Meteorol. 248: 275-294 https://doi.org/10.1016/j.agrformet.2017.10.006

Dresselhaus, T. and R. Hückelhoven. 2018. Biotic and abiotic stress responses in crop plants. https://doi.org/10.3390/agronomy8110267

Duvick, D.N. 1997. What is yield? Developing Drought-and Low N-Tolerant Maize. Proceedings of a Symposium; E1 Batan, Mex. (Mexico); 25-29 Mar 1996. In ^ TDeveloping Droughtand Low N-Tolerant Maize. Proceedings of a Symposium; El Batan, Mex.(Mexico); 25-29 Mar 1996^ AEdmeades, GO Banziger, M. Mickelson, HR Pena-Valdivia, $\mathrm{CB}^{\wedge}$ AMexi- 
co, DF (Mexico)^ BCIMMYT^^ C1997 (No. 633.153 EDM. CIMMYT.). Centro Internacional de Mejoramiento de Maiz y Trigo (CIMMYT), Mexico DF (Mexico).

Edwards, I.B. 2001. Hybrid wheat. (in) The World Wheat Book, A History of Wheat Breeding, pp 1017-45, Bonjean AP and Angus WJ (Eds), Lavoisier. Inc. Paris.

Flohr B.M., J.R. Hunt, J.A. Kirkegaard and J.R. Evans. 2017. Water and temperature stress define the optimal flowering period for wheat in south-eastern Australia. Field Crop. Res. 209: 108-119 https://doi.org/10.1016/j. fcr.2017.04.012

Fufa, H., P.S. Baenziger, B.S. Beecher, I. Dweikat, R.A. Graybosch and K.M. Eskridge. 2005. Comparison of phenotypic and molecular marker-based classifications of hard red winter wheat cultivars. Euphytica. 145: 133-46. https://doi.org/10.1007/s10681-005-0626-3

Habash, D.Z., Z. Kehel and M. Nachit. 2009. Genomic approaches for designing durum wheat ready for climate change with a focus on drought. J. Exp. Bot. 60(10): 2805-2815. https://doi.org/10.1093/jxb/erp211

Heisey, P.W., M.A. Lantican and H.J. Dubin, 2002. Impacts of International Wheat Breeding Research in Developing Countries, 1966-1997, p. 4, CIMMYT, Mexico, D.F, Mexico.

Khan, M.R., M. Imtiaz, B. Ahmed, A. Munir, A.R. Rattu, Z. Facho and S. Ali. 2020. Diversity in P. striiformis populations causing the 2013 yellow rust epidemics on major wheat cultivars of $\mathrm{Pa}$ kistan. Mycologia. 15: 871-879. https://doi.org /10.1080/00275514.2020.1792263

Khan, S.N. and Hassan, G. 2018. Genetics of production traits and stripe rust resistance in bread wheat under rainfed and irrigated conditions. PhD thesis. The Uni. Of Agri. Pesh. http:// prr.hec.gov.pk/jspui/handle/123456789/10048

Khan, M.H., A. Bukhari, Z.A. Dar and S.M. Rizvi. 2013. Status and strategies in breeding for rust resistance in wheat. Agric. Sci. 4(06): 292. https://doi.org/10.4236/as.2013.46042

Lang, L. 1989. Hybrid wheat and its perspectives. Sveriges Utsadesforenings Tidskrift 99: 121124.

Li, C.F., M. Zhao, P. Liu, J.W. Zhang, J.S. Yang, J.G. Liu, K.J. Wang and S.T. Dong. 2013. Responses of main traits of maize hybrids and their parents to density in different eras of Chi- na. Sci. Agric. Sin. 46: 2421-2429 (in Chinese with English abstract).

Longin, C.F.H., J. Mühleisen, H.P. Maurer, H. Zhang, M. Gowda and J.C. Reif. 2012. Hybrid breeding in autogamous cereals. Theor. Appl. Genet. 125:1087-1096. https://doi. org/10.1007/s00122-012-1967-7

Maqbool, R., M. Sajjad, I. Khaliq, A. Rehman, A.S. Khan and S.H. Khan. 2010. Morphological diversity and trait association in bread wheat (Triticum aestivum L.). Am. Eurasian J. Agric. Environ. Sci. 8(2): 216-224.

Mette, M.F., M. Gils, C.F.H. Longin and J.C. Reif. 2015. Hybrid breeding in wheat. In Advances in Wheat Genetics: From Genome to Field (pp. 225-232). Springer, Tokyo. https:// doi.org/10.1007/978-4-431-55675-6_24

Mohsin, A.U., J. Ahmad, A.U.H. Ahmad, R.M. Ikram and K. Mubeen. 2012. Effect of nitrogen application through different combinations of urea and farm yard manure on the performance of spring maize (Zea mays L.). J. Anim. Plant Sci. 22(1): 195-198.

Naveed, N. Khan, M.A., Baloch, M.S., Arif, M., Naqvi, S.A., Khan, J. and Ali, S. 2015. Early planting date can compensate the reduction in wheat yield due to fodder cutting in dual purpose wheat. Pak. J. Agric. Sci. 52: 469-477.

Naghavi, M.R., M. Mardi, S.M. Pirseyedi, M. Kazemi, P. Potki and M.R. Ghaffari. 2007. Comparison of genetic variation among accessions of Aegilops tauschii using AFLP and SSR markers. Genet. Res. Crop Evol. 54(2): 237-240. https://doi.org/10.1007/s10722-006-9143-z

Najaphy, A., R.A. Parchin and E. Farshadfar. 2012. Comparison of phenotypic and molecular characterizations of some important wheat cultivars and advanced breeding lines. Aust. J. Crop Sci. 6(2): 326.

Nepolean, T., J. Kaul, G. Mukri and S. Mittal. 2018. Genomics-enabled next-generation breeding approaches for developing system-specific drought tolerant hybrids in maize. Front. Plant Sci. 9: 361-. https://doi.org/10.3389/ fpls.2018.00361

Peleg, Z., T. Fahima, T. Krugman, S. Abbo, D. Yakir and A.B. Korol. 2009. Genomic dissection of drought resistance in durum wheatx wild emmer wheat recombinant in breed line population. Plant Cell Environ. 32(7): 758-79. https:// doi.org/10.1111/j.1365-3040.2009.01956.x 
Perween, S., A. Kumar, B.D. Prasad and M. Choudhary. 2020. Assessment of Genetic Diversity in Rice (Oryza sativa L.) under Irrigated and Drought Stress Condition. Curr. J. Appl. Sci. Technol.112-125. https://doi.org/10.9734/ cjast/2020/v39i130487

Pickett, A.A. 1993. Hybrid Wheat-Results and Problems, Paul Parey Scientific Publication, Berlin.

Qasim, M., M. Qamer, M. Alam, and M. Alam. 2008. Sowing dates effect on yield and yield components of different wheat varieties. J. Agric. Res. 46(2): 135-140.

Ray, D.K., N.D. Mueller, P.C. West and J.A. Foley. 2013. Yield trends are insuffcient to double global crop production by 2050. PLoS One. 8: e66428. https://doi.org/10.1371/journal. pone. 0066428

Raza, H., A. Khan and N. Ahmed. 2018. Genetic analysis for some phenological and morphological traits in wheat (Triticum aestivum L.) under two different sowing windows. Appl. Ecol. Environ. Res. 17(2): 2059-2071. https://doi. org/10.15666/aeer/1702_20592071

Reynolds, M.P., J.van Beem, M. van Ginkel and D. Hoisington. 1996. Breaking the yield barriers in wheat. A brief summary of the outcomes of an international consultation.
Singh, R. P., Singh, P. K., Rutkoski, J., Hodson, D., He, X., Jørgensen, L. N., Hovmøller, M.S. and Huerta-Espino, J. 2016. Disease impact on wheat yield potential and prospects of genetic control. Annu. Rev. Phytopathol. 54: 303322. https://doi.org/10.1146/annurev-phyto-080615-095835

Singh, H., S.N. Sharma and R.S. Sain. 2004. Heterosis studies for yield and its components in bread wheat over environments. Hereditas. 141: 106-14. https://doi.org/10.1111/j.16015223.2004.01728.x

Uddin, M.S. and A. Boerner, A. 2008. Genetic diversity in hexaploid and tetraploid wheat genotypes using microsatellite markers. Plant Tissue Cult. Biotechnol. 18(1): 65-73. https://doi. org/10.3329/ptcb.v18i1.3267

Zadoks, J.C., T.T. Chang and C.F. Konzak. 1974. A decimal code for the growth stages of cereals. Weed Res. 14(6): 415-421. https://doi. org/10.1111/j.1365-3180.1974.tb01084.x

Ziska, L.H., J.A. Bunce, H. Shimono, D.R. Gealy, J.T. Baker and P.C.D. Newton. 2012. Food security and climate change: on the potential to adapt global crop production by active selection to rising atmospheric carbon dioxide. Proc. Biol. Sci. 279: 4097-4105. https://doi.org/10.1098/ rspb.2012.1005 